\title{
ARTICLE The role of orexin-1 receptor signaling in demand for the opioid fentanyl
}

\author{
Jennifer E. Fragale ${ }^{1}$, Caroline B. Pantazis ${ }^{1}$, Morgan H. James $\mathbb{D}^{1,2}$ and Gary Aston-Jones (D)
}

The orexin system is a potential treatment target for drug addiction. Orexin-1 receptor (OxR1) antagonism reduces demand for cocaine and remifentanil, indicating that orexin-based therapies may reduce demand for many classes of abused drugs. However, pharmacokinetics vary greatly among opioids and it is unclear if OxR1 antagonism would reduce demand for all opioids, particularly ones with high abuse liability. Here, we established a behavioral economics (BE) procedure to assess the effects of OxR1 antagonism on demand for the highly abused opioid fentanyl. We also investigated the utility of our procedure to predict OxR1 antagonism efficacy and relapse propensity. Demand parameters a (demand elasticity or price sensitivity of consumption, an inverse measure of drug motivation) and $Q_{0}$ (drug consumption at null cost) were assessed. The OxR1 antagonist SB-334867 (SB) decreased motivation (increased $a$ ) for fentanyl without affecting $Q_{0}$. Baseline $a$ values predicted SB efficacy, such that SB was most effective at reducing motivation (increasing $a$ ) in highly motivated rats. Baseline $a$ values predicted the amount of cued reinstatement of fentanyl seeking; this reinstatement behavior was attenuated by SB administration. These results highlight the promise of the orexin system as a treatment target for opioid addiction and emphasize the usefulness of BE procedures in the study of opioid abuse.

Neuropsychopharmacology (2019) 44:1690-1697; https://doi.org/10.1038/s41386-019-0420-x

\section{INTRODUCTION}

Six of every 10 overdose deaths in the US involve opioids [1]. Among the opioids most frequently abused by addicts is fentanyl, a short-acting synthetic opioid that is 50 times more potent than heroin [2]. The rapid increase in opioid abuse emphasizes the need for novel approaches to study addiction and a greater understanding of the neural mechanisms underlying this disorder.

Pathological demand for drug taking is a key characteristic of addiction and can be observed in addicts as their willingness to suffer strongly negative consequences in order to obtain the drug. Behavioral economics (BE) procedures provide a quantitative analysis of drug demand that is highly translational [3-7]. Drug demand can be assessed in humans using hypothetical purchasing tasks $[6,8]$, and in animal models using operant tasks $[9,10]$. BE procedures quantify demand by plotting drug consumption as a function of price. In operant tasks, price is manipulated by varying the amount of effort (lever presses) necessary to receive a fixed amount of drug [11]. A demand curve is fit to the data using an exponential demand equation [11]. This resulting curve yields two important variables: $Q_{0}$ depicts the theoretical consumption of a reinforcer when no effort is required and is also used as a measure of hedonic set point. Alpha $(a)$ is a measure of demand elasticity (price sensitivity of consumption) and is an inverse measure of motivation. Preclinical within-session BE procedures are readily used to assess pathological demand for a variety of positive and negative reinforcers [7, 12-15]. However, few such studies have applied BE procedures to the study of opioid addiction.

Data from our lab and others indicate that the orexin (hypocretin) system is a promising treatment target for drug addiction [16-20], and orexin-based therapies have been listed by the National Institute on Drug Abuse's (NIDA) Division of Therapeutics and Medical Consequences as a high priority treatment target for opioid abuse [21]. Orexins regulate a wide range of behaviors by directly acting on two G-coupled protein receptors, orexin-1 (OxR1) and orexin-2 (OxR2) receptors [22]. OxR1 signaling has been implicated in a variety of drug-seeking behaviors and plays a role in opioid addiction [23, 24]. Our lab found that stimulation of a lateral subpopulation of orexin neurons reinstated extinguished morphine place preference and that this effect was blocked by systemic pretreatment with the selective OxR1 antagonist SB-334867 (SB) [25]. Systemic pretreatment with SB also reduced heroin self-administration and attenuated cue-elicited reinstatement of heroin seeking [26]. More recently, using the within-session BE procedure we found that OxR1 blockade decreased demand for the short-acting opioid remifentanil [10]. These findings, together with evidence that OxR1 antagonists are also effective at blocking addiction-related behaviors across other drugs of abuse tested including cocaine, alcohol, and nicotine, led to the hypothesis that orexin-based therapies might represent a novel treatment approach for addiction across a wide number of drugs $[18,19,27]$.

The effect of OxR1 blockade on fentanyl demand is yet to be tested. This is important because pharmacokinetic properties such as receptor binding affinity, rate of transport across the blood brain barrier, and half-life differ between fentanyl and other opioids $[2,28,29]$, and such differences may alter reward efficacy [30]. Here, we established a within-session BE procedure to study the usefulness of OxR1 antagonism in reducing demand for fentanyl. We also assessed the effectiveness of our within-session

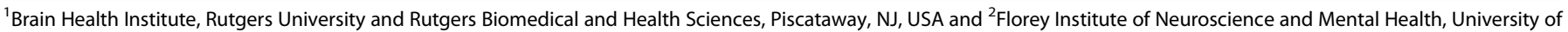
Melbourne, Melbourne, VIC, Australia

Correspondence: Gary Aston-Jones (aston.jones@rutgers.edu)

Received: 31 January 2019 Revised: 21 April 2019 Accepted: 7 May 2019

Published online: 21 May 2019 
BE procedure in predicting OxR1 antagonism efficacy as well as relapse propensity.

\section{METHODS}

Animals

Male Sprague Dawley rats were obtained from Charles River Laboratories (Kingston, NY) at $250-300 \mathrm{~g}$. Animals were pairhoused under a 12:12 h reverse light cycle (lights off 8:00 and on at 20:00). Animals were given ad libitum access to food and water. All procedures were approved by Rutgers University New Brunswick Institutional Animal Care and Use Committee and conducted in accordance with their guidelines.

\section{Surgery}

Animals were anesthetized with $2 \%$ isoflurane, administered the analgesic rimadyl (5 mg/kg, s.c.), and implanted with chronic indwelling catheters jugular vein catheters as previously described [26]. Following surgery, rats were flushed daily with the antibiotic cefazolin $(0.1 \mathrm{ml} ; 100 \mathrm{mg} / \mathrm{ml})$ and heparin $(0.1 \mathrm{ml} ; 100 \mathrm{U} / \mathrm{ml})$. Rats were allowed 1 week to recover prior to self-administration training.

\section{Drugs}

Fentanyl $\mathrm{HCl}$ powder and the selective OxR1 antagonist SB334867 were generously donated by the National Institute of Drug Abuse. Fentanyl $\mathrm{HCl}$ powder was dissolved in $0.9 \%$ sterile saline to a concentration of $8 \mu \mathrm{g} / \mathrm{ml}$. SB-334867 was prepared as previously described and injected i.p. at a volume of $4.0 \mathrm{ml} / \mathrm{kg}[10,26,31]$.

\section{Self-administration training}

Rats were trained in Med Associates operant boxes (Med Associates, St. Albans, VT, USA) fitted with 2 levers (active and inactive), a stimulus light located directly above the active lever, speaker, and house light. Operant boxes were housed in individual sound-attenuating chambers, and all boxes were controlled by Med-PC IV software (Med Associates, St. Albans, VT, USA). Rats were initially trained in $2 \mathrm{~h}$ sessions on a fixed-ratio 1 (FR-1) schedule. A response on the active lever resulted in a $3.6 \mathrm{~s}$ infusion of $0.5 \mu \mathrm{g}$ of fentanyl paired with stimulus light (white light) and tone $(78 \mathrm{~dB}, 2900 \mathrm{~Hz})$. Each infusion was followed by a 20 -s time out signaled by termination of the house light. Responses on the inactive lever were not reinforced (no infusion or cues). Rats were trained for a minimum of 10 sessions and to a criterion of $>25$ infusion for 3 consecutive sessions.

\section{Mechanical sensitivity test}

Rats were placed under plastic containers $(25 \times 15 \times 12 \mathrm{~cm})$ on a stainless-steel grid floor for $15 \mathrm{~min}$ prior to testing. Mechanical sensitivity was assessed by applying von Frey filaments to the mid-plantar surface of the rat's hind paw for $5 \mathrm{~s}$ using the up-down method [32]. A positive response was marked by a retraction of the hind paw. Baseline paw withdrawal threshold was determined by measuring withdrawal thresholds for 3 days prior to FR-1 self-administration training. Thereafter, paw withdrawal threshold was assessed prior to each self-administration session (i.e., $\sim 22 \mathrm{~h}$ withdrawal). Drug-naive rats were weight-matched controls that were subjected to identical mechanical sensitivity testing but were not trained to self-administer fentanyl.

Within-session behavioral economics procedure

Demand for fentanyl was determined using a within-session BE procedure consistent with previous studies [9, 10,31]. Briefly, animals were tested in 110-min sessions where the dose of fentanyl per infusion was decreased in successive 10-min bins on a quarter logarithmic scale $(1.12,0.63,0.36,0.20,0.11,0.06,0.04$, $0.02,0.01,0.006,0.004 \mu \mathrm{g}$ fentanyl per infusion). Demand curves were fit to the data for each session of individual subjects using an exponential demand equation [11]. Consistent with our BE procedure for remifentanil [10], curve fitting was performed by including all data points up until two bins past the point of maximal price paid (effort expended) per mg fentanyl $\left(p_{\max }\right)$.

Rats were trained for a minimum of 6 days and until stable demand was observed before any pharmacological manipulation. Animals were considered stable when demand parameters $\left(Q_{0}\right.$ and $a$ values) differed by less than $25 \%$ across three consecutive sessions. Once stable, rats were given an i.p. injection of vehicle or SB $(3,10$, or $30 \mathrm{mg} / \mathrm{kg}) 30 \mathrm{~min}$ prior to testing. Rats were given a minimum of 3 days between testing to ensure a return to baseline demand. Treatment order was assigned pseudorandomly with all rats receiving $30 \mathrm{mg} / \mathrm{kg}$ on their final test. This was done to alleviate any concerns regarding possible persistent effects of 30 $\mathrm{mg} / \mathrm{kg} \mathrm{SB}$ [33].

\section{Fentanyl + SB locomotor control}

Following $B E$ testing, a subset of rats were trained to nose poke for sucrose ( $45 \mathrm{mg}$ sucrose pellets, Test Diet, Richmond, IN, USA) on an FR-1 schedule. During each $2 \mathrm{~h}$ session, rats also received their preferred consumption of fentanyl (i.v.) as determined by their baseline $Q_{0}$ during prior BE testing. This was achieved by replaying infusions to match those received during each rat's $p_{\max }$ bin. Rats were trained for a minimum of 5 sessions and until the number of responses differed by less than $25 \%$ across 3 consecutive sessions. Thirty minutes before the next session, vehicle or SB $(30 \mathrm{mg} / \mathrm{kg})$ was given in a within-subjects, counterbalanced design with a minimum of 3 days between tests.

Extinction and cue-induced reinstatement

After BE testing, a subset of rats was exposed to 2-h extinction sessions during which responses on the active lever were no longer reinforced (no infusion or cues). Rats were trained for a minimum of 7 sessions, and until responding in the last 3 sessions was $\leq 25$ presses. During reinstatement tests, presses on the active lever were paired with fentanyl-associated cues (light and tone). Pretreatment with vehicle or SB (10 and $30 \mathrm{mg} / \mathrm{kg})$ was given in a within-subjects, counterbalanced design with a minimum of 3 days between reinstatement tests.

\section{Cued-reinstatement locomotor control}

After their final reinstatement test, the same rats were trained to lever press for sucrose ( $45 \mathrm{mg}$ sucrose pellets, Test Diet, Richmond, IN, USA) on an FR-1 schedule during 2-h sessions. Presses on the active lever resulted in pellet delivery that was not paired with cues. Each pellet delivery was followed by a 20 -s time out signaled by termination of the house light. Presses on the inactive lever were not reinforced. Rats were trained for a minimum of 5 sessions and until stable responding was observed. Rats were considered stable when the number of pellets obtained differed by less than $25 \%$ across three consecutive sessions. Vehicle or SB $(30 \mathrm{mg} / \mathrm{kg})$ was given in a within-subjects, counterbalanced design with a minimum of 3 days between tests.

\section{Data analysis}

Data are expressed as mean values \pm 1 standard error of the mean. Statistics were performed using GraphPad Prism for Mac (Version 7, GraphPad Software Inc., La Jolla, CA) with an a level of 0.05. Violations of sphericity determined by Mauchly's test were adjusted using the Greenhouse-Geisser correction. FR-1 selfadministration, paw withdrawal thresholds, body weight, and extinction data were analyzed using mixed-design ANOVAs with Bonferroni corrections as post hoc tests. One-way repeated measures ANOVAs were used to examine the effect of SB on fentanyl demand and reinstatement. Dunnett's multiple comparisons test were used as post hoc tests when permitted. Data from locomotor controls were analyzed using a paired samples $t$-tests. Two-tailed Pearson correlations were used to investigate the 
relationship between baseline demand and SB efficacy as well as the relationship between baseline demand and reinstatement.

\section{RESULTS}

Self-administration of fentanyl

Rats $(n=18)$ were first trained to self-administer fentanyl on an FR-1 schedule in $2 \mathrm{~h}$ sessions. Figure $1 \mathrm{a}$ shows self-administration data from the last 10 acquisition sessions prior to $B E$ training. The mean data $( \pm$ SEM) for the final day of self-administration training were $39.7 \pm 4.5$ infusions, $64.0 \pm 9.4$ active lever presses, and $3.3 \pm$ 0.9 inactive lever presses. On average, rats reached selfadministration criterion in $12 \pm 0.5$ sessions. Rats readily learned to discriminate between the active and inactive levers (main effect of lever type $F_{1,17}=18.75, p=0.0005$ and a lever type $\times$ session interaction $F_{9,153}=2.326, p=0.018$ ) with rats making more active than inactive lever presses across the final 9 sessions (Bonferroni correction, $p<0.05$ ).

\section{Assessment of dependence}

To assess dependence in rats self-administering fentanyl, changes in mechanosensitivity (paw withdrawal threshold) were assessed prior to each FR-1 self-administration session ( $22 \mathrm{~h}$ withdrawal). Baseline paw withdrawal thresholds (prior to self-administration training) did not differ between drug-naive and fentanyl selfadministration rats $\left(t_{14}=0.979, p=0.3438\right)$. There was a significant effect of fentanyl self-administration on paw withdrawal thresholds (Fig. $1 \mathrm{~b}$; drug $\times$ session interaction $F_{10,140}=2.679, p=0.005$ ). In rats self-administering fentanyl, paw withdrawal threshold significantly decreased from baseline after the second self-administration session (Bonferroni correction, $p<0.05$ ). Changes in paw withdrawal thresholds were not observed in drug-naive control rats tested over a similar time course. Moreover, rats self-administering fentanyl exhibited reduced weight gain compared to drug-naive control rats across the 10-day self-administration period (Fig. 1c; main effect of drug $F_{1,14}=5.9, p=0.0292$; main effect of time $\mathrm{F}_{9,126}=8.876, p<$ $0.0001)$. Weights increased compared to baseline in drug-naive control rats (Bonferroni correction, $p<0.05$ ), but not in rats selfadministering fentanyl.

Economic demand profile of fentanyl

Once fentanyl self-administration was acquired, rats $(n=18)$ were trained on a within-session BE procedure for fentanyl. Figure $1 \mathrm{~d}$ shows a demand curve generated with this procedure for a representative rat and session. Overall, curve fits were very good, with $r^{2}$ values for demand curves between 0.72 and 0.99. Mean $r^{2}$ values were $0.91 \pm 0.008$. The mean $\left( \pm\right.$ SEM) baseline $a$ and $Q_{0}$ values were $0.0834 \pm 0.0009$ and $3.433 \pm 0.351$, respectively. Consistent with demand for cocaine, no relationship was observed between demand elasticity $(a)$ and preferred intake at null cost $\left(Q_{0} ;\right.$ Fig. 1e; $\left.r^{2}=0.1294, p=0.129\right)$.

SB increases demand elasticity for fentanyl

To determine if signaling at OxR1s regulate demand for fentanyl, rats $(n=14)$ were treated with a systemic injection of vehicle or SB $(3,10$, or $30 \mathrm{mg} / \mathrm{kg})$ prior to $\mathrm{BE}$ testing. Figure $2 \mathrm{a}$ shows
A

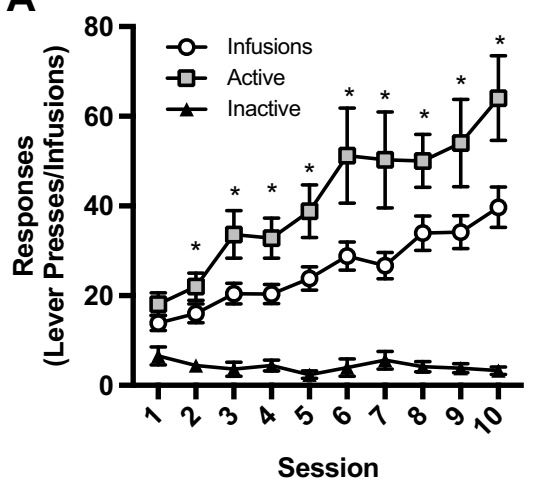

B

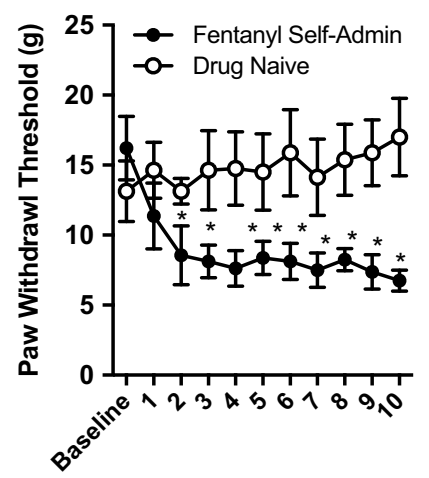

C

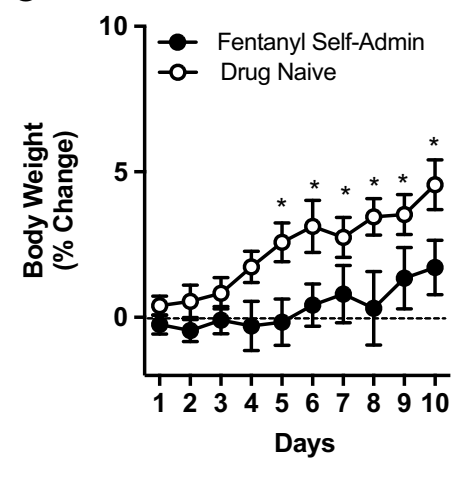

D

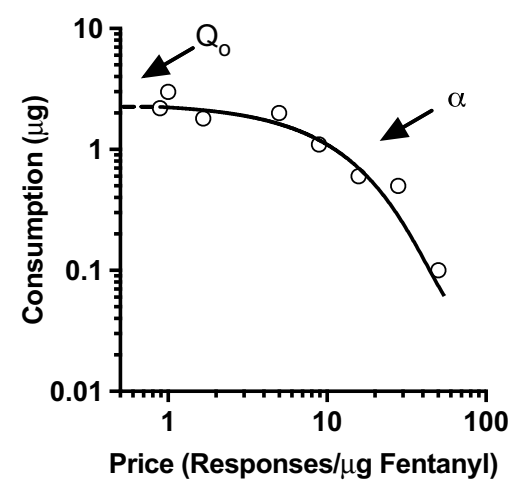

E

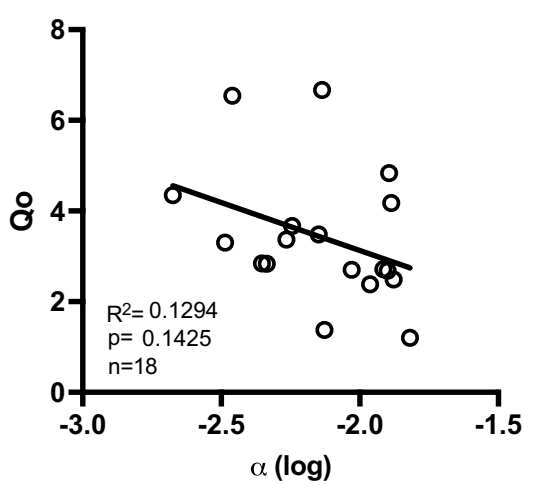

Fig. 1 Fentanyl self-administration and demand. a Rats $(n=18)$ were first trained to self-administer fentanyl on an FR-1 schedule. Rats readily learned to discriminate between the active and inactive levers, and made significantly more active vs inactive lever presses across the final 9 self-administration sessions (mixed-design ANOVA with Bonferroni comparison; $\left.{ }^{*} p<0.05\right)$. b Rats $(n=8 /$ group) exhibited a significant reduction in paw withdrawal threshold assessed by the von Frey test (mixed-design ANOVA with Bonferroni comparison; ${ }^{*} p<0.05$ ). $\mathbf{c}$ Rats selfadministering fentanyl exhibited reduced weight gain compared to drug-naive controls rats (mixed-design ANOVA with Bonferroni comparison; $\left.{ }^{*} p<0.05\right)$. d Demand curve generated from a representative subject from a single $B E$ session. e $a$ and $Q_{0}$ are independent parameters (Pearson's $r$, ns) 
representative demand curves from a subject treated with vehicle and $S B(30 \mathrm{mg} / \mathrm{kg})$ prior to $B E$ testing. SB increased demand elasticity (increased $a$; decreased motivation; Fig. $2 b ; F_{2.66,34.53}=$ $8.187, p=0.0007)$. Post hoc analysis revealed that pretreatment with SB $(30 \mathrm{mg} / \mathrm{kg})$ significantly increased demand elasticity relative to vehicle pretreatment (Dunnett's multiple comparisons test, $p=0.005)$. In contrast, systemic SB pretreatment had no effect on fentanyl consumption at null cost $\left(Q_{0}\right.$; Fig. 2c; $\left.F_{2.95,38.33}=1.155, p=0.3391\right)$.

Following BE testing, a subset of rats $(n=8)$ were trained to nose poke for sucrose on an FR-1 schedule while receiving their preferred consumption of fentanyl (i.v.) as determined by their baseline $Q_{0}$. This was done to confirm the effects of SB on demand elasticity were not due to motor suppressant effects of SB when combined with fentanyl. SB $(30 \mathrm{mg} / \mathrm{kg})$ did not alter nose poking for sucrose in rats receiving their preferred fentanyl doses (Fig. $2 \mathrm{~d}$; $\left.t_{7}=1.958, p=0.0911\right)$.

Baseline $a$ values predict SB efficacy

We previously found that baseline demand elasticity for cocaine predicts the extent to which SB reduces motivation for cocaine, such that SB is most effective in rats with inelastic demand (high motivation, low a) [34]. Accordingly, here we examined the relationship between baseline demand for fentanyl and the extent to which SB affected motivation during BE testing. Baseline $a$ was negatively correlated with SB efficacy $(30 \mathrm{mg} / \mathrm{kg})$ such that SB was most effective at increasing demand elasticity in highly motivated rats (low $a$; Fig. 3a; $r^{2}=0.3462, p=0.0269$ ). No relationship was observed between baseline $Q_{0}$ values and the efficacy of SB in increasing demand elasticity (Fig. $3 b ; r^{2}=0.00052, p=0.8047$ ).

\section{SB attenuates cue-elicited fentanyl seeking}

A subset of rats $(n=10)$ underwent extinction training and testing for cued reinstatement of fentanyl seeking. Overall rates of responding decreased over the first 7 extinction sessions (Fig. 4a; main effect of session $F_{6,54}=5.793, p=0.0001$ ). Rats initially responded more on the active vs inactive lever (main effect of lever type $F_{1,9}=66.5, p<0.0001$ ). However, active vs inactive lever presses did not differ significantly by day 7 of extinction (although there was a trend; time $\times$ lever type interaction $F_{6,54}=4.165, p=$ 0.0016; Bonferroni correction $p<0.05$ ). On average, rats reached extinction criterion in $11( \pm 1.18)$ sessions.
A

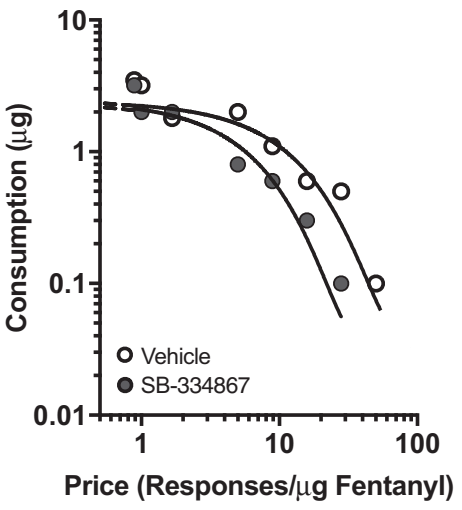

B

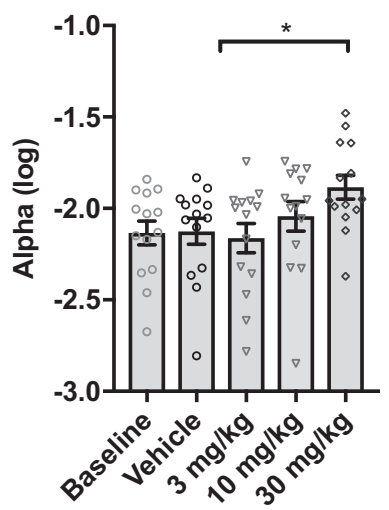

C

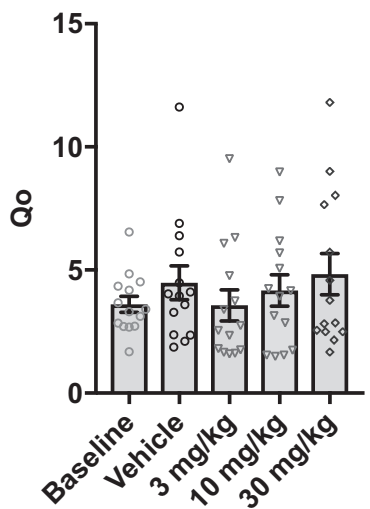

D

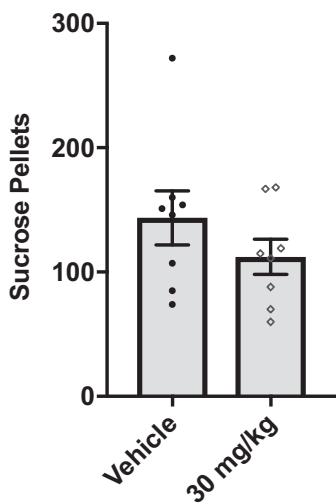

Fig. 2 OxR1 antagonism decreases demand for fentanyl. Rats $(n=14)$ were given vehicle or SB $(3,10$, or $30 \mathrm{mg} / \mathrm{kg})$ prior to BE testing. a Shown are representative demand curves from a single subject that received vehicle and SB ( $30 \mathrm{mg} / \mathrm{kg})$. b SB increased demand elasticity $(a)$ and was most effective at $30 \mathrm{mg} / \mathrm{kg}$ ( $\mathrm{rm}$-ANOVA with Dunnett's multiple comparisons test; ${ }^{*} p<0.05$ ). c SB had no effect on preferred consumption of fentanyl at null cost $\left(Q_{0}\right)(r m-A N O V A ; n s)$. d To determine if SB impaired locomotor activity, a subset of rats $(n=8)$ were trained to nose poke for sucrose on a FR-1 schedule while receiving their preferred consumption of fentanyl (i.v.). SB (30 mg/kg) had no significant effect on active lever pressing/sucrose consumption compared to vehicle-treated rats (paired samples $t$-test; ns)
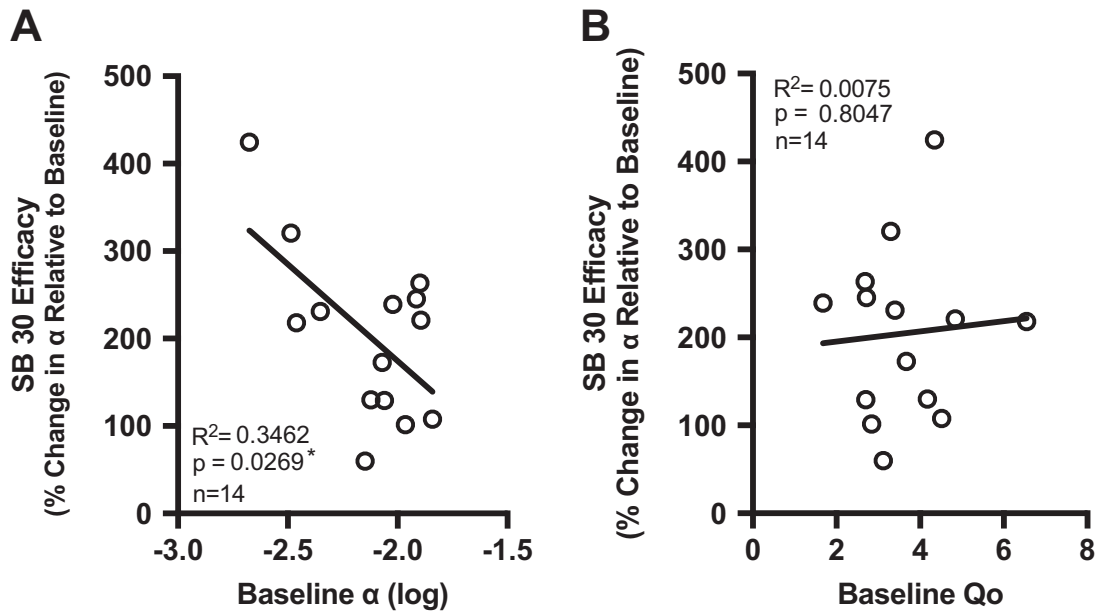

Fig. 3 Baseline $a$ values predict SB efficacy. a A negative correlation was observed between baseline $a$ values and SB (30 mg/kg) efficacy to increase $a$, indicating that SB was most effective in increasing demand elasticity (decreasing motivation) in highly motivated rats (small $a$; Pearson's $r ; p=0.0269$ ). b Baseline $Q_{0}$ values did not predict the efficacy of SB in increasing demand elasticity (Pearson's $r$; ns) 
A

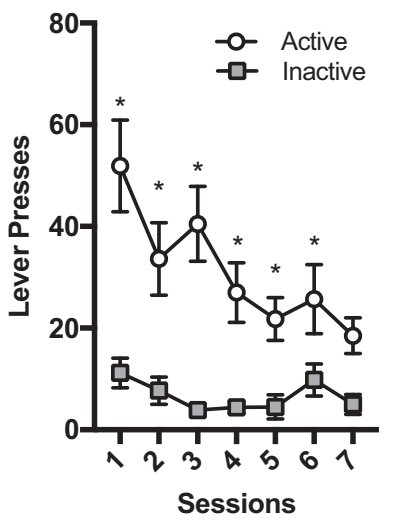

B

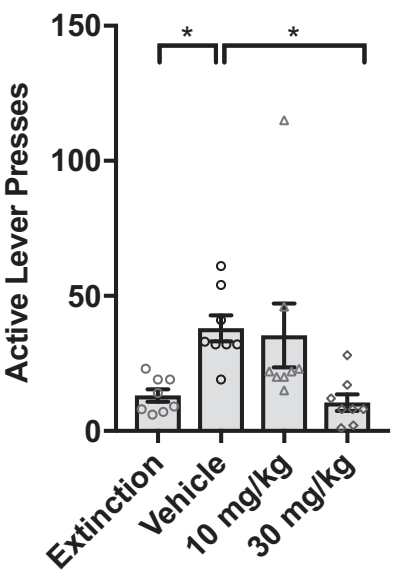

C

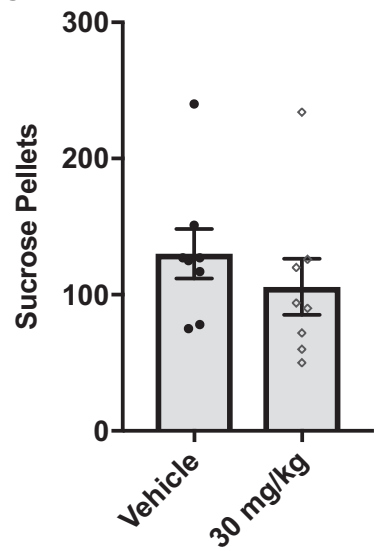

Fig. 4 OxR1 antagonism attenuates cue-elicited drug seeking. Following BE testing, lever press responding was extinguished in rats $(n=10)$. a Active lever presses gradually decreased across the first 7 extinction sessions (mixed-design ANOVA with Bonferroni comparison; ${ }^{*} p<0.05$ ). b Next, the effect of SB on cue-elicited drug seeking was assessed in a subset of rats $(n=8)$. The presentation of fentanyl-associated cues reinstated active lever pressing, and SB at $30 \mathrm{mg} / \mathrm{kg}$ attenuated cue-induced reinstatement (rm-ANOVA with Dunnett's multiple comparisons test; $\left.{ }^{*} p<0.05\right)$. c To confirm that the attenuation of cue-induced reinstatement by SB was not due to locomotor impairments, fentanyl experienced rats $(n=8)$ were trained to lever press for sucrose on an FR-1 schedule. Consumption of sucrose did not differ between SB $(30 \mathrm{mg} / \mathrm{kg})$ and vehicle-treated rats (paired samples $t$-test; $\mathrm{ns}$ )
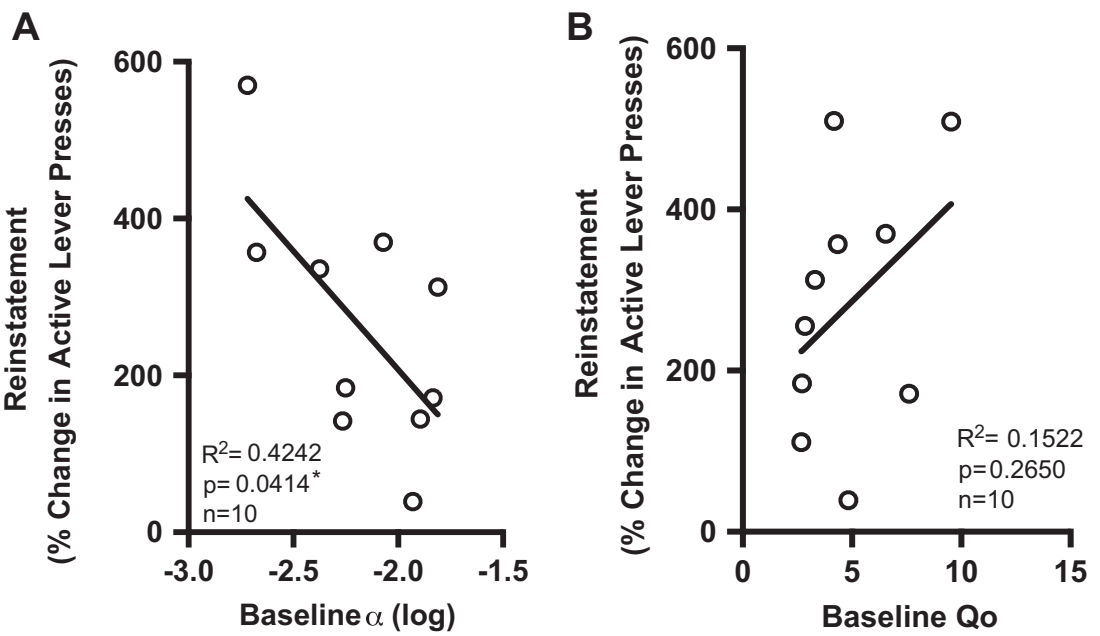

Fig. 5 Baseline $a$ values predicted cue-induced reinstatement of fentanyl seeking. The relationship between baseline $a$ and $Q_{0}$ values and reinstatement (\% change in active lever responses from final extinction session) was assessed. a Baseline $a$ was negatively correlated with reinstatement such that highly motivated rats (low $a$ ) showed greater drug seeking in response to cues (Pearson's $r ; p=0.0414$ ). b No significant relationship was observed between baseline $Q_{0}$ values and reinstatement responding (Pearson's $r$; ns)

After reaching extinction criterion, rats $(n=8)$ were given a systemic injection of vehicle or SB (10 or $30 \mathrm{mg} / \mathrm{kg})$ prior to testing for cued reinstatement of responding. SB pretreatment dosedependently attenuated cue-induced reinstatement (Fig. 4b; $F_{1.37,9.61}=6.796, p=0.0207$ ). Post-hoc analysis revealed that the presentation of fentanyl-associated cues induced a significant reinstatement of drug seeking as measured by increased responding on the active lever (extinction vs vehicle; Dunnett's multiple comparisons test, $p=0.0034)$. Compared to vehicle, SB $(30 \mathrm{mg} / \mathrm{kg})$ significantly reduced active lever presses (Dunnett's multiple comparisons test, $p=0.0009$ ). Changes in inactive lever responding were not observed $\left(F_{3,21}=1.632, p=0.2121\right)$.

We investigated the effects of SB $(30 \mathrm{mg} / \mathrm{kg})$ on sucrose selfadministration to test whether SB induced a motor impairment in fentanyl experienced rats [35]. Following their final cued reinstatement session, rats $(n=8)$ were trained to selfadminister sucrose pellets on an FR-1 schedule. Lever presses did not differ significantly between rats given vehicle vs SB (30 $\mathrm{mg} / \mathrm{kg}$ ) (Fig. $4 \mathrm{c} ; t_{7}=2.216, p=0.0623$ ). These results indicate that lever pressing for a non-drug reinforcer was not impaired by SB treatment, and that SB effects on reinstatement behavior were not due to a motor impairment.

Baseline $a$ values predict cue-induced fentanyl seeking Previous studies found that baseline $a$ values predicted other DSM-V addiction-like behaviors, including cue-induced reinstatement of cocaine seeking $[9,34]$. Accordingly, we sought to determine if this was also true for fentanyl. Baseline $a$ was negatively correlated with the degree of cue-induced fentanyl seeking (percent change in active lever presses from final extinction session) such that reinstatement behavior was greatest in highly motivated rats (Fig. $5 a ; r^{2}=0.4242, p=0.0414$ ). In contrast, no correlation with reinstatement responding was observed with baseline $Q_{0}$ (Fig. $5 b ; r^{2}=0.1522, p=0.2650$ ). 


\section{DISCUSSION}

The present study sought to determine the role of OxR1 signaling in demand for the opioid fentanyl using a within-session $\mathrm{BE}$ procedure. We found that rats self-administering fentanyl exhibit dependence-like behavior as measured by increased mechanosensitivity during withdrawal and reduced weight gain compared to drug-naive control rats. Systemic pretreatment with the OxR1 antagonist SB increased demand elasticity for fentanyl (decreased motivation) without affecting preferred consumption of fentanyl at null cost $\left(Q_{0}\right.$; hedonic setpoint). Baseline a values predicted SB efficacy, such that SB pretreatment was most effective at increasing demand elasticity in highly motivated rats. Consistent with previous findings [36], SB did not alter lever pressing for sucrose in rats that simultaneously received fentanyl, indicating that increased demand elasticity following SB pretreatment is likely not due to sedation or motor impairment. In addition, baseline $a$ values predicted the degree of cue-induced reinstatement of drug seeking, and SB dosedependently attenuated this reinstatement behavior. These results implicate OxR1 signaling in fentanyl abuse, and support the utility of $\mathrm{BE}$ procedures in assessing addiction-related behaviors for this drug.

Evidence of dependence following self-administering fentanyl Here, we show that rats self-administering fentanyl rapidly develop dependence-like behavior evident by increased mechanosensitivity during withdrawal. This is consistent with previous studies showing a reduction in paw withdrawal thresholds in heroin-dependent rats [37, 38]. The orexin system has been implicated in opioid dependence [24]. Naloxone-precipitated morphine withdrawal induces Fos expression in orexin neurons and orexin knock-out mice exhibit attenuated symptoms of morphine dependence [39]. The relationship between dependence and demand is unclear and thus it is unknown if OxR1 antagonism reduces demand for fentanyl by attenuating symptoms of dependence. Given the importance of dependence in the maintenance of opioid addiction future studies are warranted to investigate this relationship.

\section{A preferential role for OxR1 signaling in motivation}

Here, we show that OxR1 blockade decreases motivation for fentanyl (increases $a$ ) without altering free consumption $\left(Q_{0}\right)$. These results align with previous reports showing a preferential role for OxR1 signaling in regulating consumption of drug and natural reward under high-effort schedules of reinforcement [27, 40-42]. For example, OxR1 blockade reduces cocaine consumption under progressive ratio (PR) but not FR-1 schedules of reinforcement [41-43]. Consistent with these findings, SB increased demand elasticity $(a)$ for cocaine without effecting preferred consumption at null cost $\left(Q_{0}\right)[31,44]$. For natural reinforcers, such as sucrose and high fat diet, OxR1 blockade preferentially reduced consumption under high-effort schedules of reinforcement $[27,36]$. Together, these results support a role for OxR1 signaling in motivational verses hedonic processes.

There are, however, examples of OxR1 signaling regulating drug consumption under low-effort schedules of reinforcement. OxR1 receptor blockade reduces consumption of ethanol under loweffort schedules of reinforcement as well as homecage ethanol preference $[19,45,46]$. However, these results were specific to ethanol-preferring rats $[19,45]$ and high-takers [46]. This may also explain why OxR1 blockade reduces consumption of heroin under both low and high-effort schedules of reinforcement [41]. Using an identical within-session BE task, we previously found that systemic SB increased demand elasticity and reduced consumption of remifentanil at null cost [10] in a correlated manner. Given the diversity in the pharmacokinetics of opioids, future studies should investigate whether the role of OxR1 signaling in opioid demand is specific to motivation.
Future studies should explore the mechanism of action by which OxR1 signaling regulates motivation for fentanyl. Previous work indicates that OxR1 signaling in ventral tegmental area (VTA) is a possibility. Intra-VTA blockade of OxR1s increases demand elasticity $(a)$ for cocaine without affecting consumption at null cost $\left(Q_{0}\right)$ [42]. However, this has yet to be demonstrated with opioids. Additional possible targets include the paraventricular thalamus (PVT) and bed nucleus of the stria terminalis (BNST), as these are densely innervated by orexin fibers, express OxR1s in abundance, and have been implicated in a variety of drug-seeking behaviors (for review see [47]).

\section{OxR1 signaling and cue-induced reward seeking}

The orexin system also seems to play a universal role in cueinduced reward seeking. Orexin neurons are activated in response to drug-associated cues and contexts $[48,49]$. This is consistent with previously published reports showing that the OxR1 is necessary for cue-induced reinstatement of seeking for heroin, remifentanil, cocaine, ethanol, nicotine, and sucrose $[10,26,41,46,48]$. Here, we show that OxR1 antagonism also attenuates cue-induced reinstatement of extinguished fentanyl seeking. The role for OxR1 signaling in motivation (above) is consistent with this role in relapse to drug seeking; evidence from our lab indicates that the OxR1 may play a particularly important role in the motivation afforded to drug-associated stimuli [31]. Here, we show that OxR1 antagonism has no effect on responding for sucrose. This indicates that the effects of SB on cue-induced reinstatement (or demand responding) were not due to nonspecific, motoric drug effects. These results indicate that OxR1 signaling plays a strong role in cue-induced drug seeking, and OxR1 antagonism may be clinically useful in maintaining abstinence.

\section{Demand elasticity and the efficacy of orexin-based} pharmacotherapies

We found here that baseline $a$ values for fentanyl are correlated with SB efficacy. This aligns with previous studies showing that OxR1 antagonism preferentially reduced drug-seeking behaviors in highly motivated rats $[34,45,46]$. SB is most effective at decreasing cocaine motivation in rats with high baseline demand [34] and highly motivated rats are also more sensitive to lower doses of SB [44]. Together with the current study, these findings point to an increased reliance on OxR1 signaling for the maintenance of motivated behavior in highly motivated individuals.

It is important to note that OxR2 signaling may also regulate drug taking in situations of high motivation or dependence, in addition to OxR1 signaling studied here. For example, systemic administration of the OxR2 antagonist $\mathrm{NBI}-80713$ reduced heroin self-administration in highly motivated rats given long, but not short access to heroin [50]. Given that OxR2 signaling mediates aspects of stress and arousal, these results may reflect the recruitment of stress circuits under conditions of increased motivation [51]. Future studies should explore the role of OxR2 signaling in demand for fentanyl under conditions of increased motivation (e.g., long or intermittent access selfadministration).

Demand elasticity and addiction propensity

Demand elasticity provides a potential cross-species behavioral biomarker of addiction propensity [3-6]. Demand elasticity is readily assessed in clinical and subclinical populations using hypothetical purchasing tasks which determine an individual's willingness to consume a substance at various price points [3$6,8]$. Similar to the present study, a demand curve can be fitted to these data using an exponential demand equation. Demand elasticity in humans predicts symptom severity as well as relapse rates for nicotine, alcohol, and cocaine abuse $[3,4,6]$. Moreover, 
demand elasticity for prescription pain relievers predicts DSM-V symptom severity in young adults [5]. Fentanyl abuse has yet to be assessed in humans using $B E$, but this approach should be considered in future studies given the rise in fentanyl-related overdose deaths. Here, we show that baseline $a$ values for fentanyl predict cue-induced fentanyl seeking. This is consistent with previously published reports showing that baseline $a$ values for cocaine are predictive of other DSM-V relevant addiction-like behaviors in rats including compulsive responding, drug seeking during initial absence, and cue-induced reinstatement $[9,34]$.

\section{Conclusions}

Here, we show that OxR1 signaling regulates motivation to consume fentanyl and cue-induced fentanyl seeking. We also show that baseline $a$ values predict SB efficacy and cue-induced fentanyl seeking. Taken together, our findings support the promise of OxR1 antagonists as novel pharmacotherapies to combat the opioid epidemic. Furthermore, our results illustrate the usefulness of $\mathrm{BE}$ procedures in identifying individuals that may benefit best from orexin-based pharmacotherapies and those with the most severe cases of opioid abuse.

\section{FUNDING AND DISCLOSURE}

This work was supported by NIH postdoctoral fellowship (K12 GM093854) to JEF, NIH graduate fellowship (F31DA042588) to CBP, National Health and Medical Research Council of Australia C.J. Martin Fellowship (No. 1072706) and National Institute on Drug Abuse (NIDA; K99DA045765) Fellowships to MHJ, and by a U.S. Public Health Service award from NIDA to GA-J (R01 DA006214). The authors declare that the research was conducted without any commercial or financial relationships that could be considered a potential conflict of interest.

\section{ACKNOWLEDGEMENTS}

The authors would like to thank Veronica Behman for her assistance in performing behavioral experiments for this study.

\section{ADDITIONAL INFORMATION}

Publisher's note: Springer Nature remains neutral with regard to jurisdictional claims in published maps and institutional affiliations.

\section{REFERENCES}

1. Rudd RA, Seth P, David F, Scholl L. Increases in drug and opioid-involved overdose deaths-United States, 2010-2015. MMWR Morb Mortal Wkly Rep. 2016;65:1445-52.

2. Volpe DA, McMahon Tobin GA, Mellon RD, Katki AG, Parker RJ, Colatsky T, et al. Uniform assessment and ranking of opioid mu receptor binding constants for selected opioid drugs. Regul Toxicol Pharmacol. 2011;59:385-90.

3. MacKillop J, Goldenson NI, Kirkpatrick MG, Leventhal AM. Validation of a behavioral economic purchase task for assessing drug abuse liability. Addict Biol. 2018;24:303-14.

4. Bruner NR, Johnson MW. Demand curves for hypothetical cocaine in cocainedependent individuals. Psychopharmacology. 2014;231:889-97.

5. Pickover AM, Messina BG, Correia CJ, Garza KB, Murphy JG. A behavioral economic analysis of the nonmedical use of prescription drugs among young adults. Exp Clin Psychopharmacol. 2016;24:38-47.

6. MacKillop J, Murphy JG, Ray LA, Eisenberg DT, Lisman SA, Lum JK, et al. Further validation of a cigarette purchase task for assessing the relative reinforcing efficacy of nicotine in college smokers. Exp Clin Psychopharmacol. 2008;16:57-65.

7. Bickel WK, DeGrandpre RJ, Higgins ST. Behavioral economics: a novel experimental approach to the study of drug dependence. Drug Alcohol Depend. 1993;33:173-92.

8. Murphy JG, MacKillop J, Skidmore JR, Pederson AA. Reliability and validity of a demand curve measure of alcohol reinforcement. Exp Clin Psychopharmacol. 2009;17:396-404.
9. Bentzley BS, Jhou TC, Aston-Jones G. Economic demand predicts addiction-like behavior and therapeutic efficacy of oxytocin in the rat. Proc Natl Acad Sci USA. 2014;111:11822-7.

10. Porter-Stransky KA, Bentzley BS, Aston-Jones G. Individual differences in orexin-I receptor modulation of motivation for the opioid remifentanil. Addict Biol. 2017;22:303-17.

11. Hursh SR, Silberberg A. Economic demand and essential value. Psychol Rev. 2008;115:186-98.

12. Fragale JE, Beck KD, Pang KC. Use of the exponential and exponentiated demand equations to assess the behavioral economics of negative reinforcement. Front Neurosci. 2017;11:77.

13. Christensen CJ, Silberberg A, Hursh SR, Roma PG, Riley AL. Demand for cocaine and food over time. Pharmacol Biochem Behav. 2008;91:209-16.

14. Hursh SR. Behavioral economics of drug self-administration and drug abuse policy. J Exp Anal Behav. 1991;56:377-93.

15. Bickel WK, Yi R, Mueller ET, Jones BA, Christensen DR. The behavioral economics of drug dependence: towards the consilience of economics and behavioral neuroscience. Curr Top Behav Neurosci. 2010;3:319-41.

16. Baimel C, Bartlett SE, Chiou LC, Lawrence AJ, Muschamp JW, Patkar O, et al. Orexin/hypocretin role in reward: implications for opioid and other addictions. $\mathrm{Br}$ J Pharmacol. 2015;172:334-48.

17. Sharf R, Sarhan M, Dileone RJ. Role of orexin/hypocretin in dependence and addiction. Brain Res. 2010;1314:130-8.

18. Kenny PJ. Tobacco dependence, the insular cortex and the hypocretin connection. Pharmacol Biochem Behav. 2011;97:700-7.

19. Lawrence AJ, Cowen MS, Yang HJ, Chen F, Oldfield B. The orexin system regulates alcohol-seeking in rats. Br J Pharmacol. 2006;148:752-9.

20. Prasad AA, McNally GP. Effects of vivo morpholino knockdown of lateral hypothalamus orexin/hypocretin on renewal of alcohol seeking. PLoS One. 2014;9: e110385.

21. Rasmussen K, White DA, Acri JB. NIDA's medication development priorities in response to the Opioid Crisis: ten most wanted. Neuropsychopharmacology. 2018:44:657-9.

22. Sakurai T, Amemiya A, Ishii M, Matsuzaki I, Chemelli RM, Tanaka H, et al. Orexins and orexin receptors: a family of hypothalamic neuropeptides and $\mathrm{G}$ proteincoupled receptors that regulate feeding behavior. Cell. 1998;92:573-85.

23. Narita $M$, Nagumo $Y$, Hashimoto $S$, Narita $M$, Khotib J, Miyatake $M$, et al. Direct involvement of orexinergic systems in the activation of the mesolimbic dopamine pathway and related behaviors induced by morphine. J Neurosci. 2006;26:398-405.

24. Sharf R, Guarnieri DJ, Taylor JR, DiLeone RJ. Orexin mediates morphine place preference, but not morphine-induced hyperactivity or sensitization. Brain Res. 2010;1317:24-32.

25. Harris GC, Wimmer M, Aston-Jones G. A role for lateral hypothalamic orexin neurons in reward seeking. Nature. 2005;437:556-9.

26. Smith RJ, Aston-Jones G. Orexin/hypocretin 1 receptor antagonist reduces heroin self-administration and cue-induced heroin seeking. Eur J Neurosci. 2012;35: 798-804.

27. Borgland SL, Chang SJ, Bowers MS, Thompson JL, Vittoz N, Floresco SB, et al. Orexin A/hypocretin-1 selectively promotes motivation for positive reinforcers. J Neurosci. 2009;29:11215-25.

28. Inturrisi CE. Clinical pharmacology of opioids for pain. Clin J Pain. 2002;18:S3-13.

29. Hug CC Jr., Murphy MR. Tissue redistribution of fentanyl and termination of its effects in rats. Anesthesiology. 1981;55:369-75.

30. Wade CL, Vendruscolo LF, Schlosburg JE, Hernandez DO, Koob GF. Compulsivelike responding for opioid analgesics in rats with extended access. Neuropsychopharmacology. 2015;40:421-8.

31. Bentzley BS, Aston-Jones G. Orexin-1 receptor signaling increases motivation for cocaine-associated cues. Eur J Neurosci. 2015;41:1149-56.

32. Chaplan SR, Bach FW, Pogrel JW, Chung JM, Yaksh TL. Quantitative assessment of tactile allodynia in the rat paw. J Neurosci Methods. 1994;53:55-63.

33. Brodnik ZD, Alonso IP, Xu W, Zhang Y, Kortagere S, Espana RA. Hypocretin receptor 1 involvement in cocaine-associated behavior: therapeutic potential and novel mechanistic insights. Brain Res. 2018. (in press)

34. James MH, Bowrey HE, Stopper CM, Aston-Jones G. Demand elasticity predicts addiction endophenotypes and the therapeutic efficacy of an orexin/hypocretin1 receptor antagonist in rats. Eur J Neurosci. 2018. https://doi.org/10.1111/ ejn.14166.

35. Reiner DJ, Fredriksson I, Lofaro OM, Bossert JM, Shaham Y. Relapse to opioid seeking in rat models: behavior, pharmacology and circuits. Neuropsychopharmacology. 2018;44:465-77.

36. Cason AM, Aston-Jones G. Role of orexin/hypocretin in conditioned sucroseseeking in rats. Psychopharmacology. 2013;226:155-65.

37. Edwards S, Vendruscolo LF, Schlosburg JE, Misra KK, Wee S, Park PE, et al. Development of mechanical hypersensitivity in rats during heroin and ethanol 
The role of orexin-1 receptor signaling in demand for the opioid fentanyl JE. Fragale et al.

dependence: alleviation by $\mathrm{CRF}(1)$ receptor antagonism. Neuropharmacology. 2012;62:1142-51.

38. Park PE, Schlosburg JE, Vendruscolo LF, Schulteis G, Edwards S, Koob GF. Chronic CRF1 receptor blockade reduces heroin intake escalation and dependenceinduced hyperalgesia. Addict Biol. 2015;20:275-84.

39. Georgescu D, Zachariou V, Barrot M, Mieda M, Willie JT, Eisch AJ, et al. Involvement of the lateral hypothalamic peptide orexin in morphine dependence and withdrawal. J Neurosci. 2003;23:3106-11.

40. Hollander JA, Pham D, Fowler CD, Kenny PJ. Hypocretin-1 receptors regulate the reinforcing and reward-enhancing effects of cocaine: pharmacological and behavioral genetics evidence. Front Behav Neurosci. 2012;6:47.

41. Smith RJ, See RE, Aston-Jones G. Orexin/hypocretin signaling at the orexin 1 receptor regulates cue-elicited cocaine-seeking. Eur J Neurosci. 2009;30:493-503.

42. Espana RA, Oleson EB, Locke JL, Brookshire BR, Roberts DC, Jones SR. The hypocretin-orexin system regulates cocaine self-administration via actions on the mesolimbic dopamine system. Eur J Neurosci. 2010;31:336-48.

43. Boutrel B, Kenny PJ, Specio SE, Martin-Fardon R, Markou A, Koob GF, et al. Role for hypocretin in mediating stress-induced reinstatement of cocaine-seeking behavior. Proc Natl Acad Sci USA. 2005;102:19168-73.

44. James MH, Stopper CM, Zimmer BA, Koll NE, Bowrey HE, Aston-Jones G. Increased number and activity of a lateral subpopulation of hypothalamic orexin/hypocretin neurons underlies the expression of an addicted state in rats. Biol Psychiatry. 2018;85:925-35.

45. Moorman DE, Aston-Jones G. Orexin-1 receptor antagonism decreases ethanol consumption and preference selectively in high-ethanol-preferring Sprague-Dawley rats. Alcohol. 2009;43:379-86.

46. Moorman DE, James MH, Kilroy EA, Aston-Jones G. Orexin/hypocretin-1 receptor antagonism reduces ethanol self-administration and reinstatement selectively in highly-motivated rats. Brain Res. 2017;1654:34-42.

47. James MH, Mahler SV, Moorman DE, Aston-Jones G. A decade of orexin/hypocretin and addiction: where are we now? Curr Top Behav Neurosci. 2017;33:247-81.

48. Plaza-Zabala A, Flores A, Maldonado R, Berrendero F. Hypocretin/orexin signaling in the hypothalamic paraventricular nucleus is essential for the expression of nicotine withdrawal. Biol Psychiatry. 2012;71:214-23.

49. Moorman DE, James MH, Kilroy EA, Aston-Jones G. Orexin/hypocretin neuron activation is correlated with alcohol seeking and preference in a topographically specific manner. Eur J Neurosci. 2016;43:710-20.

50. Schmeichel BE, Barbier E, Misra KK, Contet C, Schlosburg JE, Grigoriadis D, et al. Hypocretin receptor 2 antagonism dose-dependently reduces escalated heroin self-administration in rats. Neuropsychopharmacology. 2015;40:1123-9.

51. Harris GC, Aston-Jones G. Arousal and reward: a dichotomy in orexin function. Trends Neurosci. 2006;29:571-7. 